\title{
Dos estudos de laboratório aos estudos de coletivos heterogêneos, passando pelos gerenciamentos econômicos
}

MICHEL CALLON ${ }^{1}$

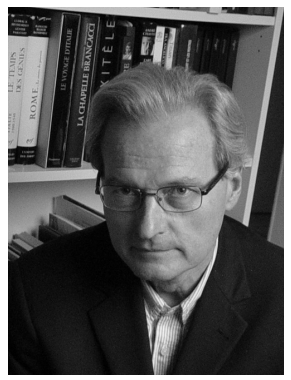

* Entrevista a Antonio Arellano Hernández² e Ivan da Costa Marques ${ }^{3}$, em 21 de agosto de 2007.

Antonio e Ivan: Como você vê o panorama atual do campo dos estudos CTS (ciência- tecnologia-sociedade)?

Michel: Houve, do meu ponto de vista, no transcurso dos últimos quinze anos, várias transformações significativas no campo CTS. A questão sobre a direção dos temas novos que são explorados nos estudos CTS se expressou bem na decisão da Society for Social Studies of Science de publicar um novo manual (handbook) que atualizasse os temas expostos naquele publicado em 1994 por Sheila Jasanoff, Trevor Pinch e outros. ${ }^{4}$ Nos últimos quinze anos os interesses precedentes dominantes no campo CTS mudaram em, pelo menos, quatro aspectos.

1 Professor do Centre de Sociologíe de l'innovation de la École Nationale Supérieur de Mines de Paris 2 Professor-pesquisador da Facultad de Ciências Políticas y Administración Pública de la Universidad Autônoma Del Estado de México

3 Professor Associado da Universidade Federal do Rio de Janeiro - Agradecimentos ao NCE/UFRJ pelo apoio à atuação no campo CTS

4 Jasanoff, Sheila; Markle, Gerald E.; Pinch, Trevor J. 1994. Handbook of Science and Technology Studies. London. Sage 
1. O primeiro é que a onda de trabalhos de pesquisa consagrados ao estudo da "ciência e tecnologia tal como se faz" diminuiu; não sei se isto é uma boa decisão, mas hoje se manifesta um desinteresse significativo pelos estudos de laboratório e das atividades científicas propriamente ditas. No entanto, esse desinteresse foi compensado pelos estudos dos coletivos de pesquisa.

Assim é que, agora, nos damos conta de que os laboratórios são somente um elemento de dispositivos mais extensos e de que, para compreender a dinâmica da produção de conhecimentos e de técnicas, não basta interessar-se somente pelas atividades de laboratório e pelo que os cientistas fazem, mas é importante abordar também o conjunto de coletivos heterogêneos profissionais e sociais que participam, de uma maneira ou de outra, na concepção, elaboração e transporte das inovações.

Desde há pouco tempo, no campo CTS, mas também na ciência econômica, nas ciências cognitivas e em outras disciplinas, estão proliferando trabalhos que se interessam por coletividades heterogêneas de pesquisa e inovação nos quais o laboratório não é mais o foco central das pesquisas. Cabe esclarecer que estes estudos não são um retorno ao estudo das comunidades científicas do estilo da sociologia mertoniana, mas que se trata de um interesse nos coletivos heterogêneos de pesquisa e inovação.

Simultaneamente se está tomando consciência da importância da ação e cognição distribuída (ACD). Com a noção ACD se entende que a ação e o conhecimento não estão localizados no cérebro humano, mas que se encontram distribuídos em dispositivos materiais não-humanos. Graças à idéia de ACD desfez-se, de um só golpe, um dos pontos de discussão em torno da Teoria Ator-Rede (TA-R) sobre a importância que esta concedia aos dispositivos técnicos e não-humanos. Nesta direção, as ciências cognitivas fizeram muito para mostrar a importância da ACD, o que permitiu avançar no estudo da produção coletiva de conhecimentos.

2. O segundo aspecto é que os estudos CTS não haviam contribuído realmente para enriquecer a Sociologia. Entendia-se que o domínio dos 
estudos CTS era um movimento das ciências sociais, interessado nas ciências e nas técnicas, mas não se via de modo preciso que aporte os estudos CTS poderiam trazer para as ciências sociais. Agora está mais claro que os trabaIhos CTS e, sobretudo, aqueles realizados em torno do tema da agência, fazem aportes e contribuições importantes para a Sociologia, a Antropologia e a Psicologia, renovando a concepção social do ser humano e da ação.

No passado, os estudos CTS mostraram como se podia socializar os objetos e os não-humanos, bem como as conseqüências da socialização dos objetos e das técnicas. Aproveitando esta experiência, agora os instrumentos desenvolvidos no campo CTS aplicam-se ao conhecimento da agência humana e, por conseqüência, do ser humano. De acordo com os estudos CTS recentes, a partir do momento em que a materialidade está compreendida no coletivo, a análise da cognição e da ação são feitas com base em premissas materiais e, portanto, abordadas do mesmo modo que os coletivos; esta é uma das razões pelas quais há agora muitos trabalhos dirigidos para a saúde humana e particularmente para as deficiências. Chama muito a minha atenção que, graças à focalização em novos temas de pesquisa, o campo CTS está tendo muito impacto nas ciências sociais e humanas.

3. O terceiro aspecto é que os pesquisadores CTS se estão interessando por campos de atividade que há alguns anos pareciam distantes de seu objeto tradicional. Por exemplo, há um número crescente de trabalhos que abordam as relações ciência-tecnologia-política para compreender como as instituições políticas e seus procedimentos se transformam pelo fato de que a ciência e a técnica são fonte de controvérsias e conflitos, de modo que os conhecimentos e os procedimentos mudam a maneira de conceber o político nas instituições. Assim, as relações entre as tecnociências e o político não são mais de exterioridade. Encontramo-nos verdadeiramente diante de uma redistribuição de isto que chamamos ciência e política em torno a instituições que agora permitem retrabalhar esta diferenciação. 
Creio que o trabalho em torno à ciência econômica é outro bom exemplo da maneira como os pesquisadores CTS estão abordando novas questões. Agora está clara a linha de trabalhos que atualmente se realizam sobre a contribuição da ciência econômica na constituição das atividades econômicas em si mesmas e sobre o papel das tecnologias e da materialidade na construção dos mercados.

No próximo manual (handbook) que, aparecerá em 2008, será interessante apreciar, entre outros, os trabalhos sobre as relações entre ciência, política e movimentos sociais; entre saúde, handicap, biossociabilidade e grupos concernentes. Todos estes temas estão agora no coração dos novos estudos CTS e têm alcances maiores do que os trabalhos anteriores.

4. O último aspecto se refere à diminuição das preocupações e quadros teóricos comuns no campo CTS. Pode-se dizer que esse campo foi vítima de seu próprio êxito, pois, tendo exportado muitos de seus resultados, suas metodologias e seus conceitos, não se consolidou como uma especialidade no sentido clássico do termo, com um objeto de estudo bem delimitado. O encanto do campo CTS é que não se encontra aí gente como especialistas da Economia, da Epistemologia, da Sociologia, da Política, etc., mas que se trata de uma reunião de gente e interesses simultâneos no cognitivo-instrumental e no social. Desde logo esta dispersão é, ao mesmo tempo, sua grande debilidade.

Durante os próximos anos, haverá um problema de definições no campo, que pode derivar, seja para 1) já uma profissionalização do programa CTS e a constituição de um campo de pesquisa com fronteiras e objetos de estudos específicos e particulares; ${ }^{5}$ ou bem para 2) sua evaporação ou dissolução logo após ter cumprido a função histórica de chamar a atenção

5 Michel comenta: "Talvez uma posição emblemática do interesse em institucionalizar o campo CTS seja a posição de Sheila Jasanoff de querer profissionalizar um campo que seria perfeitamente identificável, com seus objetos, métodos e técnicas". 
das ciências sociais para certos temas ignorados; ou ainda para, finalmente, 3) sua continuação como uma espécie de ágora ou fórum aberto com entradas e saídas, nas quais a gestão deste campo seja completamente particular, devido, sua resistência a ser dominado.

Antonio e Ivan: No panorama que você acaba de traçar, qual é o lugar dos trabalhos conduzidos pelo Centro de Sociologia da Inovação (CSI) da École de Mines de Paris?

Michel: Nós seguimos a evolução do campo, ainda que em certas ocasiões a tenhamos provocado. Nossa característica é que, durante essa evolução passamos, sem cessar, dos temas metodológicos aos teóricos.

Na história do CSI pode-se constatar que os trabalhos foram dos métodos quantitativos como a cientometria ${ }^{6}$ à teoria social como a teoria atorrede, passando por conteúdos como a inovação, a subjetividade e, mais recentemente, a agência. Interviemos, a partir de uma perspectiva CTS, em temas como a saúde e as ações das associações de enfermos; mais recentemente abordamos temas como a ciência econômica, o mercado e as relações Ciência-Política.

A trajetória do CSI corresponde à história e à dinâmica do campo CTS com todos os seus paradoxos. O CSI não administrou uma renda decorrente da situação dos alcances de suas pesquisas nem seguiu a constituição de uma especialidade, e tampouco decidiu levar uma vida confortável. Ao invés disto, seguimos o movimento amplo da dinâmica geral dos estudos CTS, o que nos conduziu a nos desinteressar de certas questões, sobre as quais havíamos adquirido certas competências e reconhecimentos, para explorar novos campos e temas. ${ }^{7}$ Outros centros de pesquisa seguiram, de

6 A cientometria foi um tema importante dos estudos CTS ao redor de há quinze anos. Embora agora esteja praticamente desaparecida do campo CTS, foi retomada por economistas e gestores.

7 Michel disse: "Temos muitos estudantes de doutorado e pós-doutorado que são atraídos para aprender sobre a TA-R, mas, ao chegar, dão-se conta de que, no CSI, fazem-se outras coisas e há outros interesses, hipóteses, etc." 
alguma forma, uma evolução similar à nossa, acompanhando os desenvolvimentos de outros centros e fazendo o próprio campo evoluir. Trata-se de centros de pesquisa, dentre eles o CSI, e de alguns pesquisadores que jogaram a carta da exploração de novas perguntas e campos, do emprego de instrumentos que mostraram sua fecundidade no estudo da ciência e das técnicas em outros campos de conhecimento e da incorporação de novos objetos de estudo, e não, a carta da reprodução e repetição de trabalhos antigos.

Antonio e Ivan: Gostaríamos de saber como você representa o conjunto de seus seguidos trabalhos depois da década de 1980. Você retraça uma ou várias linhas de interesse ou se trata de um interesse com várias entradas e saídas?

Michel: Individualmente tem-se a tendência a considerar que se mudou muito, que se passa de um tema a outro e que o que se faz agora é muito diferente daquilo que se fez anteriormente. Neste sentido se responderia a pergunta expressando certa evolução, dizendo que, nos anos 1980, trabalhei sobre a inovação técnica e a maneira como, ela reconstruía a sociedade; que me interessei pelas questões teóricas como a teoria da tradução pelos métodos quantitativos e me interessei por temas específicos como as associações de enfermos, os grupos concernentes, a Economia e a democracia técnica.

Poderia contar uma história que mostrasse que houve uma evolução e muitas mudanças, mas esta seria uma forma falsa de descrever o que se passou. Devo dizer que, quando me solicitaram reeditar certos textos que escrevi quando era jovem, fiquei impressionado ao dar-me conta de que, ao final, repeti muito, embora tivesse ainda mudado de tema. A questão não é simples, pois evoca quais são as constantes que permitem explicar como, mudando muito, não se muda tanto.

1. Então, a primeira hipótese, ou convicção permanente que encontro em muitos dos trabalhos que pude fazer, é aquela que se expressou bem na chamada teoria ator-rede, segundo a qual não se pode compreender a ação humana, e não se pode compreender a constituição de coleti- 
vos, sem levar em conta a materialidade, as tecnologias e os não-humanos. Eu diria que isto forma a base contínua de meus trabalhos e aparece nos estudos sobre os mercados, os grupos de pacientes, etc.

2. A segunda constante se relaciona com a noção de tradução, e creio que apesar de muito trabalhada, ao final, pouco se explorou. Trata-se de uma noção tanto simples quanto fundamental, pois me parece que não podemos descrever a ação, partindo de fontes de origem que são pontos, estruturas ou agentes, mas sim, através da circulação de um certo número de entidades que são mais importantes que os pontos ou as estruturas. Na circulação, as relações são mais interessantes que os pontos relacionados, mas essas relações não se referem ao sentido formal do termo mas, sim, às coisas que circulam. Agora se entende que a idéia de tradução se associa à idéia de circulação. Essa idéia não havia sido expressa assim de forma tão nítida no texto sobre a sociologia da tradução ${ }^{8}$, mas, no texto das redes tecno-econômicas (Réseaux technico-économique et irréversibilités) ${ }^{9}$, mencionei de modo mais claro a necessidade de descrever o que circula em uma rede.

Um problema é que usamos durante muito tempo o termo rede sociotécnica apesar de ser este confundido com o de rede social. As redes sociais são configuradas por pontos e relações identificáveis; diferentemente, nas redes sociotécnicas, desejamos conhecer as traduções e as coisas que se deslocam entre os pontos. A implicação importante na rede sociotécnica reside em que se quer saber o que é transportado entre os pontos, conhecer como são e de que maneira ocorrem os deslocamentos, o que está circulando, apreciar o que está em causa, o que está-se fabricando como identidade, a natureza do que se desloca, etc. A focalização teó-

8 Callon, M. 1986. "Pour une sociologie de la traduction. La domestication des coquilles SaintJacques et des marins pêcheurs", L'Année sociologique.

9 Callon, M. 1991. "Réseaux technico-économique et irréversibilités", en: Law, J. Sociology of Monsters. N.Y. Routledge. p.132-161 
rica e a metodologia interessada no que circula permite conhecer de que matéria o social está feito e seguir sua dinâmica. Então, a idéia de tradução corresponde à circulação e transporte, a tudo o que faz que um ponto se ligue a outro pelo fato da circulação.

Vendo retrospectivamente, a TA-R teve um efeito negativo em nossas aproximações e análises realistas de redes, pois nos distanciava da noção de tradução, entendida também por aquilo que circula. Pode ser que isso fosse inevitável, mas agora é tempo de voltar a este interesse teórico exclusivo que devemos ter pelo que circula.

3. A terceira constante de nosso foco de interesse se refere à elucidação da agência (agency). Esta é uma questão ainda aberta no campo do campo CTS, e eu utilizo o termo "agenciamento sociotécnico" (agencement sociotécnique) para descrever a grande diversidade de formas de agência. Aqui o problema não é saber se os seres humanos são dotados de intenção, se são capazes de tal ou qual forma de conhecimento, se são capazes de calcular, se são altruístas ou egoístas. Digamos que não está em debate a capacidade de agenciamento dos seres humanos. A questão consiste em saber quais são os agenciamentos que existem e que são capazes de fazer, de pensar e de dizer, a partir do momento em que se introduz nestes agenciamentos, não só o corpo humano mas os procedimentos, os textos, as materialidades, as técnicas, os conhecimentos abstratos e os formais, etc. Neste sentido temos agenciamentos muito diferentes uns dos outros e que são capazes de fazer coisas igualmente diferentes. Por exemplo, a questão muito clássica de saber se uma versão de seres humanos orientados pelo egoísmo, pelo cálculo, é uma versão antropologicamente mais verdadeira do que aqueles orientados pela solidariedade e pelos intercâmbios. Encontramos que, para responder a esta situação, é necessário interessar-se pelos agenciamentos, pois, de acordo com o que escrevi recentemente, há agenciamentos que são egoístas, calculadores e outros que, ao contrário, são agenciamentos altruístas, solidários, etc., mas isso depende 
da maneira como estão constituídos os agenciamentos. O agenciamento tem a virtude de designar a agência e de não reduzi-la ao corpo humano ou aos instrumentos que prolongam o corpo humano, mas de designá-la nos conjuntos de configuração de arranjos em que cada elemento esclarece os outros e permite compreender porque o agenciamento atua de certa maneira. Assim, um mercado econômico é um agenciamento, mas também um agente econômico é um agenciamento e, para compreender por que um agenciamento funciona de tal maneira ou de outra, é necessário descrever precisamente a história deste agenciamento.

Sobre este tema, tive certa reticência a considerar que havia algo que parecia uma natureza humana histórica do tipo pelo qual se interessam as ciências humanas clássicas, pois o que está em jogo no agenciamento é um assunto antropológico. Quero dizer, trata-se de saber o que é um ser humano quando se encontra formando parte de um agenciamento. De modo que, isto que chamamos ser humano se transforma em permanência. Por isso, os estudos sobre as deficiências é um tema interessante porquanto conduz a uma reflexão ao estado puro sobre o que pode fazer um ser humano e sobre a importância dos agenciamentos sociotécnicos para compreender o que pode fazer um ser humano, do que ele é capaz de pensar, de antecipar, de reivindicar, etc. Não obstante, os disabilities studies não levaram a sério a idéia de que não há senão desabilidades e seres humanos diferentes uns dos outros em situação de diferentes agenciamentos, de modo que o que existe nos disabilities studies é a sugestão de uma continuidade de agenciamentos. Creio que o tema das deficiências é um dos setores mais promissores para as ciências humanas e para os pesquisadores que, a partir da noção de tradução, consideramos que uma agência sem a passagem por outra coisa (que pode ser um não-humano, uma técnica, etc.) não é uma agência humana. A agência limitada a um ser humano não alude a um ser humano. O ser humano está incorporado em operações de 
tradução, quero dizer, um ser humano se encontra sempre incluído em uma dinâmica de agenciamento.

Antonio e Ivan: Uma versão anterior de seu trabalho sobre a tradução mantinha a distinção entre humanos e não-humanos. A nosso juízo, essa distinção limitava a proposta traducionista, pois se limitava aos dois elementos compreendidos pela própria epistemologia modernista. Como você aprecia agora essa distinção?

Michel: Em geral, as ciências sociais e humanas consideraram que existe uma assimetria modernista antológica entre seres humanos e não-humanos. Por um lado, os seres humanos estão dotados de subjetividade, de intencionalidade, de vontade, possuem linguagem articulada, podem formar-se representações, e se pode adicionar a essa lista tudo o que se pode dizer dos humanos, e, por outro lado, que uma tecnologia, um objeto, um instrumento, e um não-humano é um ente passivo e faz o que se lhe indica realizar. Desde logo se reconhece que o não-humano pode eventualmente introduzir algum desvio da ação. Faz isto, no entanto, por conta de sua inércia, sua textura, sua constituição, mas, não de maneira ativa.

No início do nosso trabalho, a separação de humanos e não-humanos era útil pois se tratava de repatriar os objetos aos humanos. Então, o primeiro ponto que se havia de fazer a respeito do conjunto das ciências sociais era dizer ... sim! os artefatos atuam, ainda que não como os seres humanos. Naquele momento se tratava de se afastar daquela posição estruturante modernista das ciências sociais e humanas, que consistia em uma partição antológica entre seres humanos e os outros, pois se não se aceitava a partição, corria-se o risco de ser considerado animista ou, talvez, um molusco; neste tempo, tratava-se de mostrar que os não-humanos atuam de certa maneira e contribuem para constituir a ação coletiva. Mas uma vez que se marcou este ponto, é necessário desembaraçar-se radicalmente da oposição entre humanos e não-humanos, que é uma distinção constringente, historicamente marcada e que corresponde ao modernismo, quero dizer, à 
convicção, segundo a qual, há duas categorias de entidades no cosmos, a saber: os humanos e os outros.

A partir do momento em que dissemos que a ação passa através dos coletivos distribuídos, rechaçamos a oposição entre humanos e não-humanos e aparecem todas as diferenças. Assim, em lugar de haver uma grande dicotomia entre humanos e não-humanos, apreciam-se muitíssimas diferenças de agências e de ação. A grande vantagem deste enfoque é que não temos que escolher entre duas categorias de agência (humana ou instrumental), mas simplesmente observar a decolagem de uma multidão de agências diferentes que estão ligadas ao fato de que há numerosos agenciamentos possíveis que atuam diferentemente. E que pode-se estudar tudo isso empiricamente.

O princípio blooriano de simetria sustenta a grande divisão (uma grande dicotomia) entre humanos e os outros, mas, com a noção de agenciamento, passamos a uma tolerância generalizada que deixa existirem todas as agências possíveis. Desde logo não desconhecemos que há relações de dominação entre as agências e que algumas delas são capazes de impor formas de agenciamento sobre outras agências, ou de excluir outras agências ou formas de agenciamento, etc. O mercado econômico e a política desempenham um papel importante nesta geopolítica do agenciamento e das agências. De modo que vocês têm razão ao observar a questão. Eu diria que a distinção entre humano e não-humano é simplesmente uma fórmula para irritar os sociólogos que sustentam a grande divisão. Não obstante, agora já não temos necessidade de manter esta distinção, pois a substituímos por uma proliferação de agenciamentos e agências diferentes.

Antonio e Ivan: Já faz tempo que você se interessa pela antropologia econômica. Seu texto sobre o teste do mercado na TA-R em $1997^{10}$ e o livro 
"The Laws of the Markets"11, em 1998, manifestam esse interesse. Você pode descortinar suas reflexões a respeito dos estudos sobre os mercados? Michel: Esse interesse já dura algum tempo e tem dois pontos.

1. Primeiro, com Fabian Muniesa e Donald Mackensie, retomamos em um livro a noção de performatividade para discutir a contribuição da disciplina 'Economia'12 para a constituição da atividade econômica e dos mercados econômicos. Discutimos essa questão desde "The Laws of the Markets" e ela se relaciona com o ponto sobre o papel da materialidade nas agências. Justapondo o assunto da performatividade da Economia com o da materialidade das agências, chegamos ao que se conhece como 'dispositivos de mercado' (market devices) que nos serve para apresentar o caráter estruturante dos dispositivos técnicos e dos elementos materiais no processo que dá forma às atividades e mercados econômicos. ${ }^{13}$

Penso que, no interior da Sociologia Econômica e do estudo dos mercados econômicos, há uma corrente bem identificada chamada performativity program que descreve de maneira imperfeita e incompleta o que queremos fazer. Creio que, com o tempo, esta corrente produzirá efeitos importantes sobre a evolução da Sociologia Econômica. É provável que, devido à sua proximidade com a Sociologia, a Sociologia Econômica tenha-se concentrado na importância das instituições, da regra, das redes sociais, das relações sociais e se tenha ocupado com denunciar o caráter ideológico e falso do saber econômico. Mas nesta resposta ao "que fazer?" ela subestimava a importância da materialidade e dos dispositivos sociotécnicos na

11 Callon, M. 1998. The laws of the markets. Oxford. Blackwell.

12 Nota de Antonio e Ivan: Callon fez uso da expressão "disciplina 'economia'" para ressaltar a diferença entre 'ciência econômica' (economics na língua inglesa) e 'atividade econômica' (economy na língua inglesa).

13 Trevor Pinch and Richard Swedberg (eds). 2007. Living in a Material World: On Technology, Economy, and Society. Cambridge. MIT Press. 
organização dos mercados, havia abandonado completamente a idéia de que a Ciência Econômica, como disciplina, podia desempenhar um papel na construção de mercados e, finalmente, não considerava que uma ciência não é somente uma descrição do que existe, mas que é também uma maquinaria poderosa que permite fazer existir o que descreve - este último ponto é justamente o que os estudos CTS mostraram, desde há muito tempo, para outras disciplinas.

Neste sentido, fazemos notar que o que é certo para as ciências naturais é também certo para as ciências econômicas e sociais, de modo que não há sociedade sem a Sociologia nem Estado sem as ciências políticas, como tampouco há atividade econômica no sentido organizado e reflexivo do termo sem a disciplina 'Economia'. A Sociologia econômica havia simplesmente esquecido duas coisas. Primeiro, que a Ciência Econômica, independentemente de sua veracidade ou falsidade, contribui para construir a atividade econômica e, segundo, que não se pode compreender a atividade econômica sem as técnicas e os componentes materiais. Então, o que contribuímos com nosso trabalho é que mais sociólogos economistas se interessam agora pelo papel da ciência econômica, da materialidade e dos componentes técnicos.

2. Esta linha de trabalho não se tornou propriamente um campo de pesquisa, porém uma sensibilidade para os estudos dos efeitos das ciências sociais e das técnicas sobre a organização das atividades econômicas que, pode-se perceber, começa a ter um certo eco entre sociólogos, e, com isso, transformamos profundamente a ciência econômica. Um dos aspectos que me interessa muito deste movimento de transformação é a visão aberta da atividade econômica e de suas conseqüências. Há vários pontos interessantes, mas agora quero referir-me ao desempenho da maneira de conceber as atividades econômicas e os mercados econômicos. Isso oferece uma capacidade de ação radicalmente nova sobre a economia, que consiste na experimentação. Agora não estamos simplesmente diante do habitual dilema entre manter a estrutura ou mudar a estrutura econômica, 
seja que aceitemos o capitalismo, ou seja que lutemos contra ele, respectivamente. Agora estamos diante de uma situação em que a noção de experimentação assume um papel capital se considerarmos que o saber que desenvolvemos e que as tecnologias que concebemos contribuem poderosamente para organizar o que chamamos atividade econômica.

Afastando o debate habitual entre a manutenção da estrutura ou sua transformação radical, situamo-nos em uma situação de experiências locais nas quais o saber sociológico, o saber econômico, o projeto da engenharia, as materialidades, os dispositivos, etc. servem para testar certas idéias sobre a economia e certas tecnologias que intervêm na organização da economia. Esta perspectiva renova a concepção do impacto da política sobre a Economia e é uma das razões pelas quais Fabian Muniesa, Donald Mackensie e eu continuamos a explorar o papel do saber econômico, das teorias econômicas e das técnicas sobre a organização das atividades econômicas.

Antonio e Ivan: Seus trabalhos sobre a Economia mostram que a expressão geral da lei do mercado dos economistas convencionais é contraditória porque cada mercado particular está cuidadosamente definido, regulamentado, constrangido, e isto é assim não por ação de um Estado que limitaria o jogo livre dos atores, mas sim por ação dos próprios atores. Poderia elaborar suas opiniões a respeito disto?

Michel: A questão é muito complexa e, antes de respondê-la propriamente, é necessário dizer que, adotando o ponto de vista sobre a relação entre a ciência econômica e os mercados mencionado na resposta anterior, aparece primeira-mente o fato da grande diversidade de organização possível dos mercados e das atividades econômicas; o segundo fato é que as regularidades e as leis repertoriadas na expressão do funcionamento destes arranjos são leis locais e temporais. Por isto, no texto das leis dos mercados, com "s" (The Laws of the Markets), aludimos à capacidade de apresentação da experimentação sobre as leis construídas sobre regularidades e suas margens de manobra. 
1. Respondendo a sua pergunta, meu primeiro comentário é que o Estado intervém na organização de mercados de modo variável e, como dizem muitos sociólogos, não há uma oposição entre mercado e Estado. O Estado participa na constituição dos mercados, de modo que não há economias que estariam do lado do Estado e outras, do lado do mercado. Na configuração atual, não há mercado sem Estado nem Estado sem mercado. Quero dizer, existem múltiplas maneiras de implicar o Estado na constituição das atividades econômicas, maneiras diferentes de organizar o mercado e formas de definir o que deve ser a ação do Estado. Isto libera consideravelmente a oposição convencional entre as economias reguladas pelo Estado e as que simplesmente seriam enquadradas por alguma regulamentação geral, organizadas essencial-mente pelo mercado de modo auto-regulado.

2. O segundo comentário é que a diversidade de princípios nas formas de organização econômica não significa necessariamente que esta diversidade se expresse concretamente nas formas de agência econômica. No último capítulo do livro "The Laws of the Markets" introduzi a noção de convergência, segundo a qual se pode mostrar que, dadas certas condições, há certas formas de organização da atividade econômica que acabam por impor-se. Então, isto que chamamos economia de mercado é o resultado da convergência de diferentes programas econômicos, políticas sociais, etc. que compartem um certo número de pressupostos comuns sobre a maneira de organizar os mercados e as atividades econômicas. Justamente a teoria econômica neoclássica desempenhou um papel importante na unificação de diferentes programas. Então temos, de um lado, a diversidade de princípios de formas de organização que é acessível à experimentação e, do outro lado, a convergência e a homogeneização das formas de organização ligadas ao fato de que uma série de programas antropológicos diferentes, nitidamente sobre a linha da teoria econômica, convergem para privilegiar uma forma de organização em relação a outras e, por conseqüência, uma forma de agência econômica hegemônica. A possibilidade de rom- 
per essa hegemonia ligada à convergência de diferentes programas depende dos espaços de experimentação que são abertos para experimentar formas diferentes de organização, de agências econômicas diferentes e de implicação entre o mercado e o Estado igualmente diferentes. O fundamental, nestas histórias, reside na possibilidade de experimentação em que as ciências sociais, o Estado, etc. se encontram implicados.

Antonio e Ivan: Você poderia elaborar a afirmação que se encontra na página 255 do livro The Laws of the Markets (Blackwell - 1998): "Sem transbordamentos não seria possível adicionar valor localmente; assim a única maneira de impedir completamente a 'engenharia reversa' seria paralisar completamente toda a atividade industrial e comercial" ? ${ }^{14}$

Michel: Se fosse necessário levar em conta todas as conseqüências ligadas às atividades econômicas, então o cálculo seria infinito porque seria necessário investigar e considerar todas as possibilidades de transbordamentos (overflows), dar conta de todos os grupos que estão implicados nos overflows, e conseqüentemente, jamais seria possível concluir os cálculos dos efeitos produzidos pela atividade econômica. É devido a que ignoramos deliberadamente os efeitos secundários (adotando a linguagem da ciência econômica, as externalidades) que podemos concluir os cálculos. Vejamos isto com um exemplo. Normalmente consideramos que um contrato é um ato realizado entre dois agentes e não, entre três; consideremos, por exemplo, a situação de um agricultor de uma zona agrícola ribeirinha situada 100 km águas abaixo da localização de uma indústria e que sofre de contaminação produzida pelas atividades ligadas ao contrato firmado entre dois agentes, digamos os donos da indústria e um governo local. O problema é que os efeitos do contrato não se limitam jamais às duas partes signatárias, pois 'reverse engineering' would be to bring all industrial and commercial activity to a standstill.I" 
existem overflows. Mas se se tivesse que levar em conta todos os efeitos, como a contaminação que sofre o agricultor do exemplo, não haveria nenhuma atividade econômica possível, já que a atividade econômica, por definição, fecha o cálculo em certo momento. Imediatamente, como sempre, há um resto. Às vezes as terceiras partes, que não são signatárias, mas que acabam implicadas pelos efeitos do contrato, solicitam ser levadas em conta. O agricultor, ao perceber que sua atividade é posta em perigo pelos dejetos da indústria química que ele não havia levado em conta, diria: "esperem!, sua atividade danifica a minha, é necessário que levem em conta meus interesses e que seu contrato seja a três." Ainda assim, neste ato não se eliminam todos os outros efeitos que podem produzir-se em outros, simplesmente porque não se investiga para conhecê-los. Então há um fechamento da investigação dos efeitos, e é isso que permite que a atividade econômica se desenvolva.

Antonio e Ivan: Como se liga a idéia de overflows às externalidades positivas que estão ligadas ao conhecimento científico e técnico?

Michel: Vejamos assim. Como sou um pesquisador e publico textos, eu devo publicar para transmitir os resultados que obtenho. Esse texto circula e, a partir daí, muito rapidamente os resultados que eu obtive me escapam - isto é uma externalidade positiva, pois todos os pesquisadores que leiam esse texto e que tenham competências similares às minhas, podem beneficiar-se do resultado do trabalho que eles não fizeram. Exatamente o mesmo se passa com um artefato técnico. Se sou um fabricante de automóveis, ao vender um carro, o artefato chega às mãos de meus competidores que são especialistas de tecnologia automotiva, os quais desmontam o carro para ver como funciona e que podem copiar o que observam para utilizar os resultados da atividade de pesquisa que eu fiz. Então a 'engenharia reversa' é uma atividade que consiste em desmontar o computador ou o automóvel produzido por um competidor para apropriar-se da tecnologia. Porém ela está ligada à própria atividade econômica; para suprimi-la seria necessário 
decidir não vender o automóvel. Quero dizer que a partir do momento em que se vende um automóvel, fica-se exposto à imitação, e é por isso que digo que os overflows são constitutivos da atividade econômica; não se pode suprimi-los ou fazê-los desaparecer, a não ser que se detenha a atividade econômica. O mesmo se passa com a atividade científica; o simples fato de produzir conhecimentos, de disseminá-los, de discuti-los, de produzir artefatos e vendê-los fabrica a possibilidade de overflowing.

Antonio e Ivan: Segundo você, qual seria o lugar da pesquisa tecnocientífica e das inovações nos países denominados "periféricos" enquanto objeto de estudo CTS. Por exemplo, sobre a constituição de mercados heterogêneos, a exploração de mercados alternativos e emergentes, de inovações locais, etc.? Michel: Desde há algum tempo fui convencido, por uma série de pesquisas de colegas que fazem pesquisas pós-coloniais, do papel estratégico, nitidamente para a antropologia dos mercados, consagrado aos atuais países do "sul," ou dos que saíram de situação colonial, para compreender a realização de possíveis formas de organização de atividades econômicas.

O politólogo especialista em Egito, Tim Mitchell ${ }^{15}$ escreveu um livro marcante sobre a constituição da nação e da economia egípcia, mostrando que o Egito foi um laboratório que permitiu a países como o Reino Unido conceber e imaginar dispositivos estatísticos, formas de propriedade, etc. que foram, em seguida, transpassadas a outros países "desenvolvidos." Trabalhos similares foram realizados sobre a Índia, fazendo notar, entre várias coisas, que o saber econômico desempenhou um papel considerável na constituição das economias nacionais e que estes laboratórios de economias provaram a validade disso que se conhece como economia nacional. É necessário ir aos detalhes, mas estes trabalhos são uma demonstração convincente para entender o que foi feito pelos colonizadores nas países co-

15 Timothy Mitchell, 2002. Rule of Experts: Egypt, Techno-Politics, Modernity. University of California Press. 
lonizados para fazer existir as identidades e as economias nacionais e constituí-los de modo que possam ser consideradas como objetos sobre os quais se atua e com quem se interage, uma vez que, para dominar uma economia colonizada, é necessário primeiro constituí-la em objeto sobre o qual se possa atuar e dominar.

O fascinante é que esses trabalhos vêm completar a tarefa do que faziam os historiadores das ciências da natureza e da vida, mostrando que os países da periferia foram os laboratórios que as ciências ocidentais utilizaram e mobilizaram para coletar dados e poder constituir-se em ciências autônomas. Não se tratava de uma situação em que o saber ocidental entraria em conflito com as ciências locais, tratando de impor-se sobre elas, mas que, desde muito cedo, as ciências do centro foram elaboradas na periferia. Isso é certo no caso das ciências portuguesas nas quais Moçambique e Angola constituíam países nos quais se testava e experimentava a eficácia de certas instituições e as formas de organização da pesquisa, das quais se extraíram referências sobre as quais se elaborou o sistema científico português.

Estou convencido de que, para compreender as economias como disciplinas e o saber das ciências ocidentais, é necessário compreender como se construíram nos países da periferia e foram repatriados, e como em seguida, foram impostas nos países não ocidentais. Em todo caso, trata-se de histórias imbricadas de diversas formas de organização de saber possíveis, pelo que, para seu estudo, seria necessário ressituar-se na dinâmica de imbricação de formas de saber e de atividade econômica. Nesta tarefa, eu creio que não se trata simplesmente de aplicar uma antropologia de ciências, de técnicas econômicas elaboradas nos países ocidentais para produzir um certo número de fatos sobre a organização da ciência nos países da periferia. Não se trata disso, mas sim, de privilegiar os terrenos e as realidades da periferia porque constituem a ocasião de situar a experimentação, nas quais é mais difícil realizar e fazer aceitar princípios porque a história desses países é mais complicada, existem elementos heterogêneos que ainda são visíveis e que aparecem e deixam conseqüências abertas de 
possibilidades que parecem menos evidentes em certas economias ou instituições científicas e técnicas de países centrais.

Falar da história das economias e instituições científicas de países periféricos mostra certo tipo de evidência mais amplo de possibilidades de experimentação, de combinação, de agenciamento, e as leis parecem historicamente menos contingentes do que nos países centrais mais "desenvolvidos," nos quais a naturalização das organizações econômicas é algo que não se pode contestar facilmente. Nos países periféricos, há mais poder de impor pois a convergência nos países menos "desenvolvidos", encontra-se menos acabada. Nos países menos "desenvolvidos" há mais heterogeneidade nas formas de regulação, de organização e de definição do que deve ser um mercado econômico. A maior heterogeneidade ligada a relações complicadas de enredamento favorece a própria idéia de experimentação de novos experimentos.

Julia Elyachard, ${ }^{16}$ referindo-se ao Egito, mostra a multiplicidade possível de formas de organização da atividade econômica ligada à multiplicidade de atores que nela intervêm. Aqui, cada ator tem uma definição diferente do que é a atividade econômica. E este reencontro de programas diferentes expressa de maneira relativamente explícita e legítima por que e como resultou ser este país um laboratório privilegiado para imaginar e experimentar formas de atividade econômica e normas de atividade científica diferentes, que posteriormente se impuseram progressivamente nos países do centro. A outra questão interessante é que, nos países centrais, ainda existe também uma grande heterogeneidade. Por exemplo, se alguém se interessa pelas ações das associações de doentes, encontrará uma grande heterogeneidade de formas entre a França, Estados Unidos e Reino Unido, pois há regimes diferentes de relações entre atividade econômica e tecnocientífica.

16 Elyachar Julia, 2005. Markets of Dispossession. NGOs, Economic Development, and the State in Cairo. Durham, Duke University Press 